\title{
Outcomes of pubertal development in girls as a function of pubertal onset age
}

\author{
A German', M Shmoish'2, J Belsky ${ }^{3}$ and Z Hochberg ${ }^{4}$ \\ ${ }^{1}$ Pediatric Endocrinology, Clalit HMO and Bnai Zion Medical Center, Haifa, Israel, ${ }^{2}$ Lorry I. Lokey Interdisciplinary \\ Center for Life Sciences and Engineering, Technion - Israel Institute of Technology, Haifa, Israel, ${ }^{3}$ Department of \\ Human Ecology, University of California, Davis, California, USA, and ${ }^{4}$ Faculty of Medicine, Technion - Israel Institute \\ of Technology, Haifa, Israel
}

\author{
Correspondence \\ should be addressed \\ to Z Hochberg \\ Email \\ rprzeev@tx.technion.ac.il
}

\begin{abstract}
Background: The relationship between pubertal onset and tempo and pubertal growth is controversial. We hypothesized that the age at onset of girls' puberty predicts pubertal tempo and the rate of pubertal progression. Methods: We analyzed the data of 380 girls from the prospective Study of Early Child Care and Youth Development (SECCYD) who were recruited in the USA from 1991 to 2006 and followed from birth to age 15.5 years. We used the following indicators: thelarche age (Tanner stage B2), pubarche age (P2), menarche age (M), the age when breast (B5) and pubic hair (P5) became fully mature, pubertal growth, pubertal duration (time from B2 to B5) and pubertal progression (time from B2 to M). We clustered the girls according to B2 age into early onset (EO; $<9.4$ years), intermediate (IO; 9.4-10.5 years), late onset (LO; >10.5 years).

Results: All indicators of pubertal onset and conclusion occurred earlier in the EOs than in the LOs; yet, the differences in the age at main pubertal milestones lessened as puberty progressed: 2 years for $\mathrm{B} 2 ;-1.4$ years for $\mathrm{M} ;-1$ year for B5. In EOs, puberty was 1 year (average) longer than in LOs. Although EOs grew $7 \mathrm{~cm}$ (average) more than LOs, their heights at B5 were comparable. There was a significant relationship between the thelarche age and puberty tempo $(r=0.23, P<0.0001)$.

Conclusions: The study highlights the predictive nature of variation in the onset age of puberty on its progression and duration. These results are reassuring in this context and will add to clinicians' and parental understanding of the
\end{abstract} expected milestones of puberty.

Individual differences in pubertal maturation can be described in terms of timing (the age at onset) and tempo. Timing describes the maturation of children relative to their same-sex and same-age peers, it is determined by inter-individual differences in neuroendocrine maturation and expressed by Tanner stages of secondary sexual characteristics and the age at menarche. In contrast, pubertal tempo is an auxiliary construct that describes the pace at which girls progress from the onset of puberty to menarche and then to sexual maturity. Critical levels of adrenal androgens for pubarche and estrogens for thelarche (1) determine the onset of puberty in girls. At the conclusion of puberty, a girl's ultimate adult height and reproductive maturity is defined.

Numerous publications have addressed the timing of puberty and its relationship to adult height $(2,3)$, weight $(4,5)$, BMI $(1,6,7)$ and the adiposity rebound (8). The number of published reports on the association between timing and tempo of puberty in girls, which is the topic of this report, is small. Some investigators found that girls who started puberty early tended to reach menarche rapidly $(9,10)$, but the interval from Tanner stage B2 to peak height velocity was longer for early maturing girls than that of average or late maturing girls (10). In contrast, https://eje.bioscientifica.com https://doi.org/10.1530/EJE-17-1025
(C) 2018 European Society of Endocrinology Printed in Great Britain
Published by Bioscientifica Ltd. 
Li et al. found no evidence for an association between timing and tempo in Chinese girls (11), and Marceau et al. suggested that timing and tempo were associated in boys, but not in girls (12).

Using principles from evolutionary and developmental biology, we previously examined puberty as an evolutionary life-history stage in its developmental context (13). According to evolutionary theory, developmental and maturational traits respond to environmental cues for controlling fecundity-survival schedules and behavioral strategies that yield high survival and reproductive fitness in a given environment. We and others have suggested that the secular trend for early puberty reflects the overall quality of modern environments and allows females with a given genome to approach the extremes of their range of plasticity for puberty onset $(13,14,15)$.

Assuming that the timing and tempo of puberty are associated in a way that benefits reproductive strategy, we hypothesized that the onset age of puberty will predict pubertal progress and the growth tempo, but not the final adult height. We tested these hypotheses using data from the large cohort SECCYD (16).

\section{Patients and methods}

We analyzed data of 380 girls from the SECCYD, which was collected from 1991 to 2006 (12, 16, 17). Specifically, our analysis used reported data from the onset age of puberty (Tanner stage B2 (thelarche)) and menarche age as indices of pubertal progression (B2 to menarche), tempo and growth.

\section{Subjects}

Participants in the longitudinal NICHD SECCYD (16) were recruited from 24 hospitals in the United States; their recruitment and selection are described in detail in previous study publications $(16,18,19)$ and on the study's website https://www.nichd.nih.gov/research/ supported/seccyd. Children were followed up from birth to age151/2 years (1991-2006) with a common study protocol. Annually from ages $91 / 2$ to $151 / 2$ years (2000-2006), staging of secondary sexual characteristics was performed by a nurse practitioner or physician. We included in our report 293 (77\%) white participants, 49 (13\%) black participants and 38 (10\%) other minorities, in total 380 girls, who had the information on menarche age reported. Height, weight measurements, BMI calculation and pubertal stage assessments were made by the study's network of investigators. All study procedures were approved at the institutional review boards of each site, as previously reported (16), and parental informed consent was obtained from all participants.

\section{Pubertal development}

The pubertal development of each girl for the age 10.515.5 assessments was determined annually by a physical examination and anthropometry. The age of occurrence of each Tanner stage was determined using photos and breast bud palpation $(20,21)$. Breast palpation was not used before the age 9.5 assessments. The pubertal stage was assessed annually using Tanner criteria and the guidelines of the American Academy of Pediatrics on the assessment of sexual maturity stages in girls (22). The examiners gave a girl a lower stage rating when her sexual characteristics were between two stages. The assessment of the pubertal stage continued until their breast and pubic hair were fully developed. From age 10.5 years, the girls reported annually whether menstruation had begun and their age at first menses. The annual maternal report was used when the daughter's self-report was missing $(n=117)$.

\section{Retrospective data analysis}

Here, we investigated the age at the onset of puberty Tanner stages P2 (pubarche) and B2 (thelarche). Based on Fig. 1, all participants were divided into three clusters:

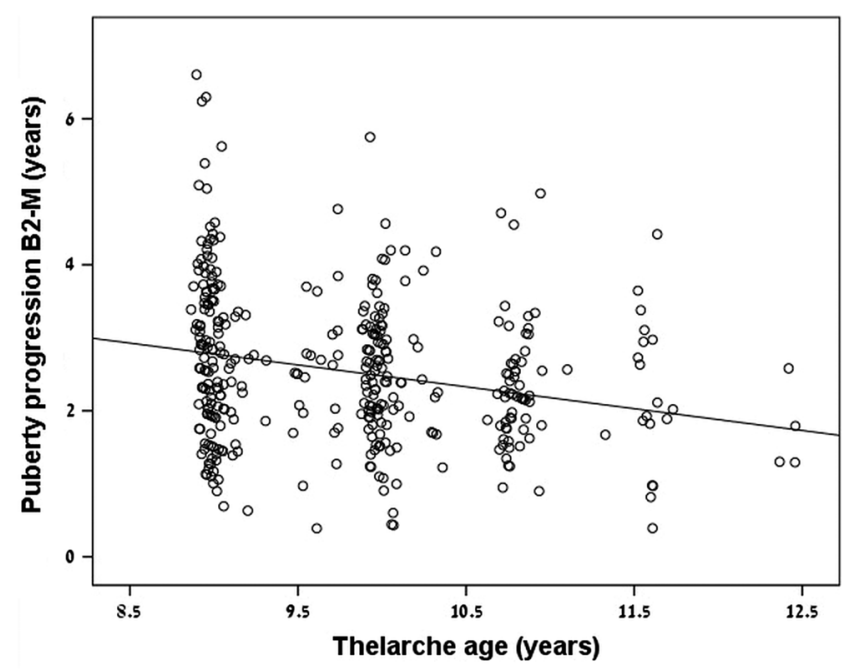

Figure 1

Pubertal progression (B2-M; years) for all four quartiles as a function of thelarche age (B2). $n=380,(B 2-M)=5.5-0.3 \times$ B2age, $r=0.23, P<0.0001$. 
Table 1 The clusters according to the age at thelarche (B2) (years; A) and quartiles of the interval from the age at thelarche to the age at menarche (years, B2-M; B).

\begin{tabular}{|c|c|c|}
\hline & $n$ & Mean \pm S.D. \\
\hline \multicolumn{3}{|l|}{ A: B2 age (years) } \\
\hline$<9.4$ (EO) & 156 & $9.0 \pm 0.1$ \\
\hline 9.4-10.5 (IO) & 138 & $9.9 \pm 0.2$ \\
\hline$>10.5$ (LO) & 86 & $11.0 \pm 0.5$ \\
\hline \multicolumn{3}{|c|}{ B: B2-M interval quartiles } \\
\hline 1 & 95 & $1.3 \pm 0.5$ \\
\hline 2 & 95 & $2.1 \pm 0.2$ \\
\hline 3 & 95 & $2.8 \pm 0.2$ \\
\hline 4 & 95 & $3.9 \pm 0.7$ \\
\hline
\end{tabular}

Data are displayed as mean \pm standard deviation.

EO, early-onset group; IO, intermediate-onset group; LO, late-onset group.

girls who showed signs of thelarche (a) before the age of 9.4 years were labeled EO, (b) from the age of 9.410.5 years were labeled intermediate onset (IO) and (c) those with thelarche after age 10.5 years were labeled as LO. We defined 'pubertal duration' as the time from age at thelarche to the appearance of Tanner stages B5 (fully mature breast), and 'pubertal progression' as the time elapsed from Tanner stage B2 to menarche (M) (17). We used the B2-M interval to divide the study's participants into quartiles. BMI for study participants was calculated at all ages.

\section{Statistical analysis}

Data were analyzed using statistical analysis software (SPSS Statistics for Windows, version 20.0, SPSS Inc.). The chronological ages, growth, the ages at menarche, pubertal duration and the rates of pubertal progression of the EOs and LOs were compared using an independent samples $t$ test. An independent samples $t$ test was also used to compare the continuous variables of the first and third B2 clusters and the first and fourth B2-M interval quartiles. Spearman's correlation coefficients were used to determine the linear association between anthropometrical parameters and the age at stages of pubertal development. A cross tabulation analysis was done to explore the relationship between the timing and the tempo of puberty and its variation. Chi-square statistics were used to test the relationship between the groups defined by age at thelarche and the groups defined by B2-M interval. Data are displayed as mean \pm standard deviation (s.D.) and statistical significance was set at 5\%.

\section{Results}

Average age at $\mathrm{B} 2$ in the entire cohort was $9.8 \pm 0.83$ years. The number of EOs was twice as many as the number of LOs (Table 1). Thelarche in the EOs happened a mean 2 years earlier than its occurrence in the LOs $(9.0 \pm 0.1$ vs $11.0 \pm 0.5$ years). Average age at menarche in the entire cohort was $12.3 \pm 1.2$ years (Table 2 ). In the EOs, pubarche and menarche also occurred early than its occurrence in the LOs. The differences in the age of the main pubertal milestones diminished as puberty progressed. For B2, the difference was 2 years, for $M$, the difference was 1.4 years and for B5, the difference was 1.0 years (Table 1 ). In the EOs, the age at pubarche $\mathrm{P} 2$ occurred $0.8 \pm 0.6$ years after the age at thelarche, and P2 coincided with the age at B2 of the LOs $(0.1 \pm 0.8$ years $)$.

Puberty progressed slower in the EOs than in the LOs (Table 3). The duration of the B2-B5 interval was longer in the EOs than in the LOs $(4.5 \pm 1.1$ years vs $3.6 \pm 0.8$ years $(P<0.001))$ with a mean difference of 1.0 years (Table 4 ). Although the EOs grew more than the LOs $(27.8 \pm 4.7 \mathrm{~cm}$ vs $20.6 \pm 3.8 \mathrm{~cm} ; P<0.001)$ during the time from $\mathrm{B} 2$ to the $\mathrm{B} 5$, their heights at the age of 15.5 years, when all participants reached B5, were comparable (Table 2).

We found a significant relationship between the age at thelarche and the rate of pubertal progression $(r=0.23$,

Table 2 Age at puberty onset (thelarche B2 and pubarche P2) and puberty end (B5 and P5) for girls with early (<9.4 years) or late (>10.5 years) B2 age and for girls whose intervals from the age at thelarche to the age at menarche (B2-M) are short (1st quartile) or long (4th quartile). Data are displayed as mean \pm s.D.

\begin{tabular}{|c|c|c|c|c|c|c|}
\hline & \multicolumn{3}{|c|}{ B2 age (years) } & \multicolumn{3}{|c|}{ B2-M } \\
\hline & $<9.4$ & $>10.5$ & Mean diff. (Cl) & 1st quartile & 4th quartile & Mean diff. (Cl) \\
\hline Thelarche age & $9.0 \pm 0.1$ & $11.0 \pm 0.5$ & $2.0(2.1,2.0)^{* *}$ & $10.0 \pm 0.9$ & $9.7 \pm 0.7$ & $0.3(0.1 ; 0.4)^{*}$ \\
\hline Pubarche age & $9.8 \pm 0.6$ & $10.9 \pm 0.8$ & $1.1(1.3,0.9)^{* *}$ & $10.2 \pm 0.8$ & $10.3 \pm 0.6$ & $-0.1(-0.2 ; 0.0)$ \\
\hline Menarche age & $11.8 \pm 1.1$ & $13.2 \pm 1.1$ & $1.4(1.7,1.1)^{* *}$ & $11.3 \pm 1.0$ & $13.4 \pm 1.0$ & $-2.1(-2.4 ;-1.8) * *$ \\
\hline Age with mature breast B5 & $13.6 \pm 1.1$ & $14.6 \pm 0.8$ & $1.0(1.3,0.8)^{* *}$ & $13.7 \pm 1.1$ & $14.1 \pm 0.5$ & $-0.4(-0.5 ;-0.2) * *$ \\
\hline Age with fully mature pubic hair P5 & $13.7 \pm 1.0$ & $14.5 \pm 0.8$ & $0.8(1.1,0.6)^{* *}$ & $13.6 \pm 1.0$ & $14.2 \pm 0.6$ & $-0.6(-0.7 ;-0.4) * *$ \\
\hline
\end{tabular}


$P<0.0001$ ) girls (Fig. 1). Data on the age of appearance of breast Tanner stage 2 did not distribute continuously because the assessments of the Tanner stages were done annually during the SECCYD (Fig. 1).

The slope of the regression line indicates that each year of early thelarche appearance increased pubertal progression by 4 months. Despite this clear evidence that an early age at thelarche prolongs and a late age at thelarche shortens pubertal progression until menarche, the variation around the depicted regression line should not be ignored. Cross tabulation of early and LO B2 clusters against short and long B2-M interval shows the heterogeneity of these two variables. Among EO girls $25.4 \%$ had short (1st quartile B2-M) and $74.6 \%$ had long (4th quartile) B2-M interval and among LO girls $44.1 \%$ had short (1st quartile B2-M) and 55.9\% had long (4th quartile) B2-M interval.

At thelarche, the EO were shorter than the LO girls $(139.9 \pm 8.5 \mathrm{~cm}$ vs $144.7 \pm 8.4 \mathrm{~cm}, \quad P<0.001)$. During puberty, the mean height difference increased to a maximum of $8 \mathrm{~cm}$ at age 12 years. Nevertheless, heights at B5 were indistinguishable: $164.4 \pm 6.1 \mathrm{~cm}$ (EOs) vs $163.9 \pm 6.7 \mathrm{~cm}$ (LOs). Growth from age $14-15$ was $2.2 \pm 2.5 \mathrm{~cm}$ and $4.0 \pm 2.9$, respectively ( $P=0.024$; Fig. 2$)$, yet, we have no growth data beyond age 15.5.

To evaluate the contribution of adiposity to the age at puberty onset and the rate of pubertal progression, we study the correlation coefficients $R$ between puberty milestones and BMI SDS as a function of age (Fig. 3). The age at B2 and M correlates significantly with the BMI at onset of puberty, and many years beforehand - as of age 3 years. Pubertal progression and duration did not correlate with the BMI at any age.

Table 3 Cross tabulation analysis on the age at thelarche and pubertal progression for early and late maturing girls and for girls whose B2-M are short (1st quartile) or long (4th quartile).

\begin{tabular}{|c|c|c|c|}
\hline & \multicolumn{2}{|c|}{ B2 groups } & \multirow[b]{2}{*}{ Total } \\
\hline & Early & Late & \\
\hline \multicolumn{4}{|l|}{ B2-M groups } \\
\hline \multicolumn{4}{|l|}{ Short } \\
\hline Count & 32 & 30 & 62 \\
\hline Expected & 40 & 22 & 62 \\
\hline \% within B2 groups & 25.4 & 44.1 & 32 \\
\hline \multicolumn{4}{|l|}{ Long } \\
\hline Count & 93 & 38 & 132 \\
\hline Expected & 86 & 46 & 132 \\
\hline$\%$ within B2 groups & 74.6 & 55.9 & 68 \\
\hline \multicolumn{4}{|l|}{ Total } \\
\hline Count & 125 & 68 & 193 \\
\hline$\%$ within B2 groups & 100.0 & 100.0 & 100.0 \\
\hline
\end{tabular}

\section{Discussion}

A common cause for referral to a pediatric endocrinologist is parental concern about early pubertal development and its consequences. The clinical question at the center of this report concerns the relationship between the age of pubertal onset, pubertal progression and tempo and adult height. SECCYD comprises data that were collected from a large sample of Caucasian girls from ten different sites in the United States (12). Using the same database, Marceau et al. modeled pubertal growth and tempo and related them to BMI, height, weight at age 12.5 years and psychological outcomes at age 15.5 years. Using two statistical models that they developed, they reported that pubertal timing and tempo were associated in boys, but not in girls (12). We come to a different conclusion. In our hands, the interval from menarche to B5 is fairly constant, and we therefore defined a new feature that we call 'puberty progression' - the tempo from B2 to menarche, which correlates negatively and significantly with $\mathrm{B} 2$ age (timing).

A limitation of SECCYD is the assessment of a breast Tanner stage; they used photos and breast bud palpation for age 10.5-15.5 assessments, breast palpation was not used before age 9.5 because it was not a methodological consideration when the study began. This might have led to an underestimation of the percentage of girls at developmental stage 2. Nonetheless, this research used a highly reliable protocol for assessing pubertal development based on instructions from the American Academy of Pediatrics Assessment of Sexual Maturity Stages in Girls (22). Moreover, it was recently confirmed that self-assessment can be validly used in evaluating sexual maturation in children (23). A second limitation is that assessments of the subjects in SECCYD were done until age 15.5 years. Therefore, we defined the last height measurement at age 15.5 years as the height at B5 and not final adult height. Three of the girls were still growing, making it possible that they will end up taller than group. We found that puberty is slower in the EOs as compared to LOs; it took almost 3 years for these girls to reach menarche and 4.7 years to complete their puberty. In contrast, we found that LOs took 2.3 years to reach menarche and 3.7 years to complete their puberty. However, we found large variation around this significant trend, and a large number of girls violated this trend. We also found that the timing and tempo of puberty substantially affect the growth pattern: the tempo and pubertal height of the EOs are greater than those of the LOs despite no difference in their height at Tanner stage 5 for breast. The slow puberty 
Table 4 Pubertal progression and duration for early and late maturing girls and for girls whose intervals from the age at thelarche to the age at menarche (B2-M); are short (1st quartile) or long (4th quartile). Data are displayed as mean \pm S.D.

\begin{tabular}{|c|c|c|c|c|c|c|}
\hline & \multicolumn{3}{|c|}{ B2 age (years) } & \multicolumn{3}{|c|}{ B2-M } \\
\hline & $<9.4$ & $>10.5$ & Mean diff. (Cl) & 1st quartile & 4th quartile & Mean diff. (Cl) \\
\hline B2-P2 interval (years) & $0.8 \pm 0.6$ & $-0.1 \pm 0.8$ & $0.9(0.7,1.1) * *$ & & & \\
\hline B2-M interval (years) & $2.8 \pm 1.1$ & $2.2 \pm 1.0$ & $0.6(0.3,0.9) * *$ & & & \\
\hline B2-B5 interval (years) & $4.5 \pm 1.1$ & $3.6 \pm 0.8$ & $1.0(0.8,1.3)$ ** & $3.7 \pm 1.0$ & $4.4 \pm 0.7$ & $-0.7(-0.8 ;-0.5)$ ** \\
\hline M-B5 interval (years) & $1.8 \pm 1.2$ & $1.4 \pm 1.2$ & $0.4(0.1,0.7)^{*}$ & $2.4 \pm 1.1$ & $0.8 \pm 0.9$ & $1.6(1.3 ; 1.9)$ ** \\
\hline Height at B2 $(\mathrm{cm})$ & $139.9 \pm 8.5$ & $144.7 \pm 8.4$ & $4.8(2.5,7.0)^{* *}$ & $139.9 \pm 11.1$ & $139.0 \pm 10.3$ & $0.9(-1.6 ; 3.5)$ \\
\hline Height at B2 (SDS) & $0.6 \pm 0.8$ & $-0.1 \pm 1.10$ & $-0.8(-1.0,-0.5) * *$ & $0.40 \pm 1.00$ & $0.31 \pm 0.93$ & $0.1(-0.1 ; 0.3)$ \\
\hline Height gain from $B 2$ to $B 5(\mathrm{~cm})$ & $27.8 \pm 4.7$ & $20.6 \pm 3.8$ & $-7.1(-8.6,-5.7) * *$ & $28.3 \pm 5.8$ & $30.7 \pm 4.3$ & $-2.4)-4.5 ;-0.3)$ * \\
\hline Height at B5 $(\mathrm{cm})$ & $164.4 \pm 6.1$ & $163.9 \pm 6.7$ & $0.5(-1.7,2.7)$ & $162.5 \pm 6.7$ & $165.6 \pm 6.09$ & $-0.5(-0.8 ;-0.1)$ * \\
\hline
\end{tabular}

$* P<0.05, * * P<0.001$, diff. difference

of EOs has been previously reported. A longitudinal study of 307 prepubertal Greek schoolgirls reported that the duration of the $\mathrm{B} 2$ to peak height velocity interval in EOs was almost twice as long of that of LOs (1.6 years vs 0.9 years) (10). Similar results have been reported from the United States (24) and Spain (25).
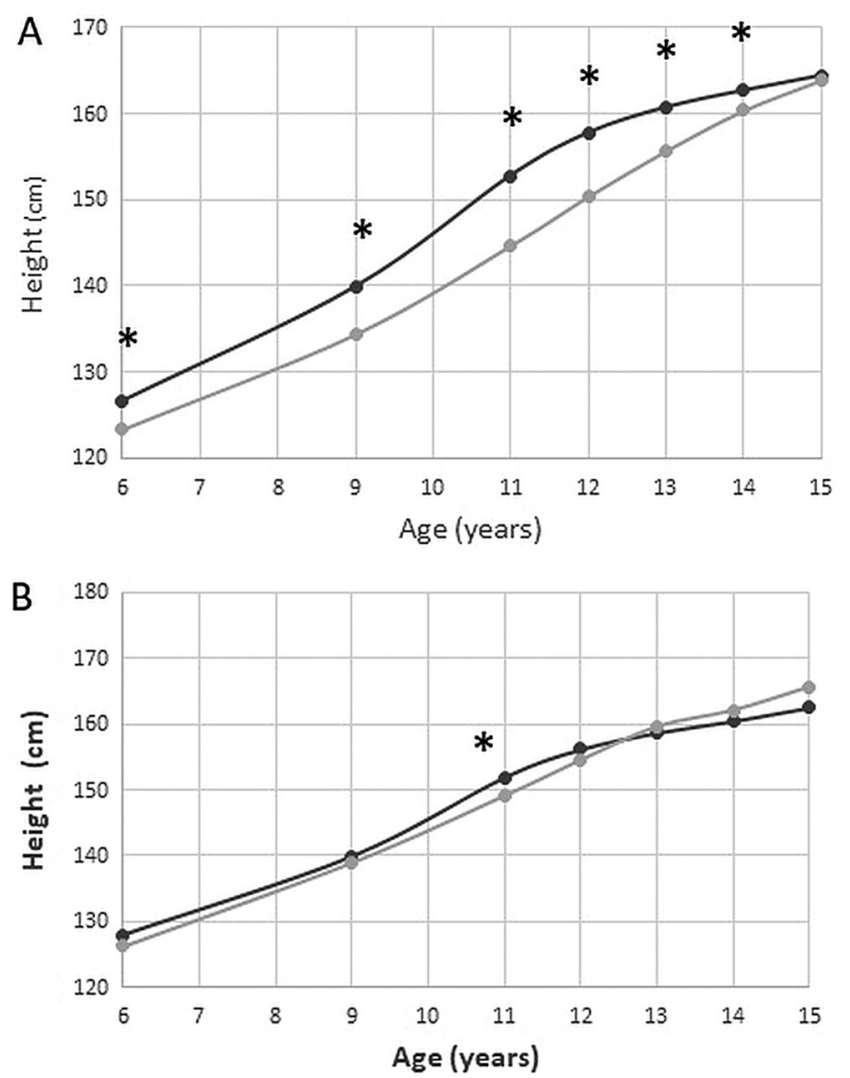

Figure 2

Mean height progression from age 6-15.5 years. (A) for girls with early (black) or late thelarche (gray); (B) for girls with a short (1st quartile, black) or long (4th quartile, gray) B2-M interval. Test, $* P<0.05$.
Whereas the primary concern of parents of daughters with an early puberty is the time to menarche, their second concern is growth and adult height of their daughters. We found that (a) early timing of puberty is buffered by a slow rate of pubertal progression in early maturers and (b) late timing of puberty is compensated for by a rapid progression in the late maturers. LlopVinolas et al. reported that girls with an early onset of puberty compensated their short height at pubertal onset by a long duration of puberty, thereby enabling additional height gain during this period (26). This finding confirms previous observations that an 'onset of puberty at 8 years of age in girls determines a slow tempo of puberty but does not affect B5 height' (25). Pantsiotou et al. found no significant difference in the peak height velocity and the adult height in 75 girls irrespective of whether they matured early, average or late (10).

The third apprehension of parents of an EO girl is developmental and psychosocial readiness. Early timing of puberty has consistently been shown to be a risk factor for girls' behavioral difficulties (26), and a combination of early pubertal onset and fast pubertal tempo predicted psychological problems $(12,27)$. We did not investigate the cognitive and social aspects of pubertal tempo and duration, but results of this study suggest the existence of a compensatory slowing of puberty, which allows for developmental readiness and minimizes psychosocial problems.

Much work has been done on the nature of the reciprocity between adiposity and puberty $(1,6,7,17)$. Our results agree with those of a recent study which found an association between BMI and thelarche and menarche (18), and we show that the correlation becomes significant at a young age of 36 months for both thelarche and menarche. However, adiposity did not correlate with pubertal tempo. Thus, the association of adiposity with 


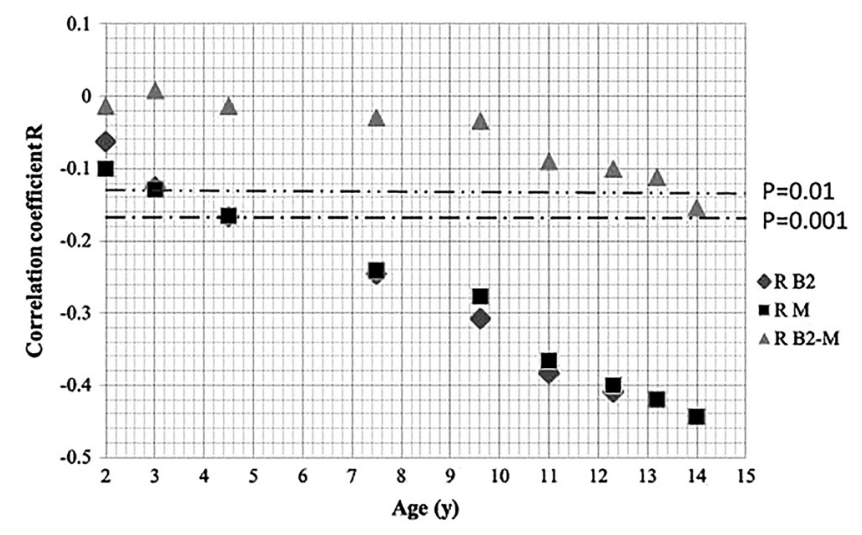

\section{Figure 3}

The correlation coefficient $\mathrm{R}$ between $\mathrm{BMI}$ at different ages and thelarche (B2, diamond), menarche (M, square) and puberty progression (B2-M, triangle). The correlation becomes significant $(P<0.01)$ when $R$ is $\leq 0.126$.

menarche age is secondary to the association between BMI and the onset of puberty.

Results of this study highlight the predictive nature of the variation in the timing of puberty. They will enhance clinicians' and parental understanding of the expected milestones of puberty and help them make rational decisions on hormonal manipulation of puberty.

\section{Declaration of interest}

The authors declare that there is no conflict of interest that could be perceived as prejudicing the impartiality of this study.

\section{Funding}

This research did not receive any specific grant from any funding agency in the public, commercial or not-for-profit sector.

\section{References}

1 Biro FM, Pinney SM, Huang B, Baker ER, Walt Chandler D \& Dorn LD. Hormone changes in peripubertal girls. Journal of Clinical Endocrinology and Metabolism 201499 3829-3835. (https://doi. org/10.1210/jc.2013-4528)

2 Heger S, Partsch CJ \& Sippell WG. Long-term outcome after depot gonadotropin-releasing hormone agonist treatment of central precocious puberty: final height, body proportions, body composition, bone mineral density, and reproductive function. Journal of Clinical Endocrinology and Metabolism 199984 4583-4590.

3 Parent AS, Teilmann G, Juul A, Skakkebaek NE, Toppari J \& Bourguignon JP. The timing of normal puberty and the age limits of sexual precocity: variations around the world, secular trends, and changes after migration. Endocrine Reviews 200324 668-693. (https:// doi.org/10.1210/er.2002-0019)

4 Dunger DB, Ahmed ML \& Ong KK. Early and late weight gain and the timing of puberty. Molecular and Cellular Endocrinology 2006 254-255 140-145.
5 Tanner-Smith EE. Negotiating the early developing body: pubertal timing, body weight, and adolescent girls' substance use. Journal of Youth and Adolescence 201039 1402-1416. (https://doi.org/10.1007/ s10964-009-9489-6)

6 Kaplowitz PB, Slora EJ, Wasserman RC, Pedlow SE \& HermanGiddens ME. Earlier onset of puberty in girls: relation to increased body mass index and race. Pediatrics 2001108 347-353. (https://doi. org/10.1542/peds.108.2.347)

7 Davison KK, Susman EJ \& Birch LL. Percent body fat at age 5 predicts earlier pubertal development among girls at age 9. Pediatrics 2003 111 815-821. (https://doi.org/10.1542/peds.111.4.815)

8 German A, Livshits G, Peter I, Malkin I, Dubnov J, Akons H, Shmoish M \& Hochberg Z. Environmental rather than genetic factors determine the variation in the age of the infancy to childhood transition: a twins study. Journal of Pediatrics 2015166 731-735. (https://doi.org/10.1016/j.jpeds.2014.11.047)

9 Apter D \& Vihko R. Premenarcheal endocrine changes in relation to age at menarche. Clinical Endocrinology 198522 753-760. (https:// doi.org/10.1111/j.1365-2265.1985.tb00165.x)

10 Pantsiotou S, Papadimitriou A, Douros K, Priftis K, Nicolaidou P \& Fretzayas A. Maturational tempo differences in relation to the timing of the onset of puberty in girls. Acta Paediatrica 200897 217-220. (https://doi.org/10.1111/j.1651-2227.2007.00598.x)

11 Li YH, Ma HM, Chen HS, Su Z, Gu YF \& Du ML. [Longitudinal study of the pattern of pubertal development in Cantonese schoolgirls]. Zhonghua Er Ke Za Zhi 200947 410-415.

12 Marceau K, Ram N, Houts RM, Grimm KJ \& Susman EJ. Individual differences in boys' and girls' timing and tempo of puberty: modeling development with nonlinear growth models. Developmental Psychology 201147 1389-1409. (https://doi. org/10.1037/a0023838)

13 Hochberg Z \& Belsky J. Evo-devo of human adolescence: beyond disease models of early puberty. BMC Medicine 201311 113. (https:// doi.org/10.1186/1741-7015-11-113)

14 Gluckman PD \& Hanson MA. Evolution, development and timing of puberty. Trends in Endocrinology and Metabolism 2006 17 7-12. (https://doi.org/10.1016/j.tem.2005.11.006)

15 Hochberg Z. Evo-devo of child growth II: human life history and transition between its phases. European Journal of Endocrinology 2009 160 135-141. (https://doi.org/10.1530/EJE-08-0445)

16 Network NECCR. The effects of infant child care on infant-mother attachment security: results of the NICHD Study of Early Child Care. Child Development 199768 860-879.

17 German A, Shmoish M \& Hochberg Z. Predicting pubertal development by infantile and childhood height, BMI and adiposity rebound. Pediatric Research 201578 445-450. (https://doi. org/10.1038/pr.2015.129)

18 Belsky J, Houts, RM \& Fearon, RM. Infant attachment security and the timing of puberty: testing an evolutionary hypothesis. Psychological Science 201021 1195-1201. (https://doi. org/10.1177/0956797610379867)

19 Belsky J, Steinberg L, Houts RM \& Halpern-Felsher BL. The development of reproductive strategy in females: early maternal harshness $\rightarrow$ earlier menarche $\rightarrow$ increased sexual risk taking. Developmental Psychology 201046 120-128. (https://doi.org/10.1037/ a0015549)

20 Belsky J, Steinberg LD, Houts RM, Friedman SL, DeHart G, Cauffman E, Roisman GI, Halpern-Felsher BL \& Susman E. Family rearing antecedents of pubertal timing. Child Development $2007 \mathbf{7 8}$ 1302-1321. (https://doi.org/10.1111/j.1467-8624.2007.01067.x)

21 Susman EJ, Houts RM, Steinberg L, Belsky J, Cauffman E, Dehart G, Friedman SL, Roisman GI \& Halpern-Felsher BL. Longitudinal development of secondary sexual characteristics in girls and boys between ages $91 / 2$ and 151/2 years. Archives of Pediatrics and Adolescent Medicine 2010164 166-173. (https://doi.org/10.1001/ archpediatrics.2009.261) 
22 Herman-Giddens ME, Slora EJ, Wasserman RC, Bourdony CJ, Bhapkar MV, Koch GG \& Hasemeier CM. Secondary sexual characteristics and menses in young girls seen in office practice: a study from the Pediatric Research in Office Settings network. Pediatrics 199799 505-512. (https://doi.org/10.1542/ peds.99.4.505)

23 Chavarro JE, Watkins DJ, Afeiche MC, Zhang Z, Sánchez BN, Cantonwine D, Mercado-García A, Blank-Goldenberg C, Meeker JD \& Téllez-Rojo MM. Validity of self-assessed sexual maturation against physician assessments and hormone levels. Journal of Pediatrics 2017186 172-178.e3. (https://doi.org/10.1016/j. jpeds.2017.03.050)

24 Biro FM, Lucky AW, Simbartl LA, Barton BA, Daniels SR, StriegelMoore R, Kronsberg SS \& Morrison JA. Pubertal maturation in girls and the relationship to anthropometric changes: pathways through puberty. Journal of Pediatrics 2003142 643-646. (https://doi. org/10.1067/mpd.2003.244)

25 Llop-Vinolas D, Vizmanos B, Closa Monasterolo R, Escribano Subias J, Fernandez-Ballart JD \& Marti-Henneberg C. Onset of puberty at eight years of age in girls determines a specific tempo of puberty but does not affect adult height. Acta Paediatrica 200493 874-879. (https://doi.org/10.1111/j.1651-2227.2004.tb02683.x)

26 Mendle J, Turkheimer E \& Emery RE. Detrimental psychological outcomes associated with early pubertal timing in adolescent girls. Developmental Review 200727 151-171. (https://doi.org/10.1016/j. dr.2006.11.001)

27 Mendle J, Harden KP, Brooks-Gunn J \& Graber JA. Development's tortoise and hare: pubertal timing, pubertal tempo, and depressive symptoms in boys and girls. Developmental Psychology 2010461341. (https://doi.org/10.1037/a0020205)

Received 13 December 2017

Revised version received 1 August 2018

Accepted 6 August 2018 